\title{
Pengaruh Medoka terhadap Motivasi dan Hasil Belajar Tema Selalu Berhemat Energi
}

\author{
Sri Supadmi ${ }^{1}$, lin Purnamasari ${ }^{2}$, Zainal Arifin $^{3}$ \\ ${ }_{1,2,3}$ PGSD Fakultas IImu Pendidikan, Universitas PGRI Semarang \\ e-mail: fon.an16@gmail.com¹, purnamasari67@gmail.com², arifinz@gmail.com³
}

\begin{abstract}
Abstrak
Tujuan yang hendak dicapai yaitu untuk mengetahui adanya pengaruh MEDOKA terhadap motivasi dan hasil belajar pada tema Selalu Berhemat Energi kelas IV SD Tambak 02 Karangdowo. Jenis penelitian ini adalah True-Experimenta dengan model Pretest-Posttest Control Group. Populasi penelitian adalah siswa siswi SD Tambak 02 Karangdowo. Sampel yang diambil adalah 44 siswa kelas III A dan III B dengan menggunakan teknik Non probability Sampling dengan jenis sampling Sampling Purposive. Data dalam penelitian ini diperoleh dengan observasi, tes dan dokumentasi. Berdasarkan Hasil penelitian menunjukan hasil posttest memiliki rata-rata lebih tinggi yaitu 82,045 pada kelas eksperimen dan 79,091rata-rata pada kelas kontrol serta hasil pretest memiliki rata-rata nilai73,863 pada kelas eksperimen dan 60,454 rata-rata pada kelas kontrol sehingga nilai uji regresi yaitu, dan uji linieritas yaitu dengan 1,89 dengan 2,85 maka dapat disimpulkan bahwa Fhitung <Ftabel berarti H0 diterima artinya terjadi persamaan linier serta perhitungan dengan uji segnifikansi yaitu 887,5 7dan 4,35, maka dapat disimpulkan bahwa Freg >Ftabel berarti Ho ditolak, artinya persamaan regresisi gnifik an diterima. Adapun besar pengaruh dari hasil uji koefisien determinasi dengan Microsoft Excel 2013 adalah sebesar 30\% sedangkan sisanya dipengaruhi oleh faktorlainya. Sehinggadapat diakatakan bahwa MEDOKA efektif atau berpengaruh terhadap motivasi dan hasil belajar siswaSD Negeri 02 Tambak.
\end{abstract}

Kata Kunci: MEDOKA, Motivasi Belajar, Hasil Belajar, IPA

\begin{abstract}
The aim to be achieved is to find out the influence of MEDOKA on motivation and learning outcomes on the theme of Always Save Energy class IV SD Tambak 02 Karangdowo. This type of research is True-Experimental with the Gruup Pretest-Posttest Control model. The study population was elementary school students Tambak 02 Karangdowo. The samples taken were 44 students in class IIIA and IIIB using the Non probability sampling technique with the type of Purposive Sampling. The data in this study were obtained by observation, tests and documentation. Based on the results of the study, the posttest results had a higher average of 82,045 in the experimental class and 79,091 on the average in the control class and the pretest results had an average value of 73,863 in the experimental class and 60,454 on the control class so that the regression test values were, and linearity test which is 1.89 with 2.85, it can be concluded that Fcount <Ftable means that $\mathrm{HO}$ is accepted, meaning that there is a linear equation after calculation with a significance test, 887.57 and 4.35, it can be concluded that Freg $>$ Ftable means Ho is rejected, meaning the regression equation is significantly accepted. The influence of the test results of the coefficient of determination with Microsoft Excel 2013 is $30 \%$ while the rest is influenced by other factors. So that it can be said that MEDOKA is effective or influences the motivation and learning outcomes of elementary school 02 Tambak students.
\end{abstract}

Keywords: MEDOKA, Learning Motivation, Learning Outcomes, Science 


\section{Pendahuluan}

Kemajuan suatu bangsa ditentukan oleh pendidikannya dan majunya pendidikan ditentukan oleh manusianya. Pendidikan merupakan salah satu sektor penting pembangunan di setiap Negara. Melalui pendidikan seseorang dapat mempelajari bagaimana cara meningkatkan dan mengembang potensi berupa intelektual, mental, sosial, emosiaonal dan kemandirian dalam kehidupan, sehingga menimbulkan manusia yang baik juga (Mudali Marga, 2018). Perkembangan pendidikan di era globalisasi ini sangatlah pesat. Peserta didik dituntut untuk aktif dan produktif dalam pembelajaran. Seperti yang telah diketahui, di Indonesia menggunakan kurikulum terbaru yaitu Kurikulum 2013 atau yang sering disebut kurtilas. Di dalam Kurikulum 2013 terdapat Kompetensi Inti (KI) dan Kompetensi Dasar (KD). IPA di SD yang merupakan standar minimum yang secara nasional harus dicapai oleh peserta didik dan menjadi acuan dalam pengembangan kurikulum di setiap satuan pendidikan. Pencapaian KI dan KD didasarkan pada pencapaian peserta didik dalam membangun kemampuan, pekerja ilmiah dan pengetahuan sendiri yang difasilitasi oleh guru. Dalam penerapannya masih bayak guru-guru yang menggunakan metode konvensional. Alasan guru dalam pembelajaran secara konvensional adalah supaya peserta didik lebih kondusif pada saat proses KBM. Pada pembelajaran konvensional guru lebih aktif dalam proses KBM sehingga kesempatan peserta didik mencoba mengembangkan kemampuan diri dan mencoba mencari pemahaman materi secara mandiri belum diterapkan atau belum diberikan kepada peserta didik.

Mata pelajaran IPA di SD memiliki tujuan sebagai berikut, (1) memperoleh keyakinan kepada Tuhan Yang Maha Esa berdasarkan keberadaan, keindahan, dan keteraturan alam ciptaan-Nya. (2) mengembangkan pengetahuan dan pemahaman konsep-konsep IPA yang bermanfaat dan diterapkan dalam kehidupan sehari-hari. (3) mengembangkan rasa ingin tahu yang saling mempengaruhi antara IPA, teknologi dan masyarakat. (4) mengembangkan ketrampilan proses untuk menyelidiki alam sekitar, memecahkan masalah, dan membuat keputusan. (5) peningkatan kesadaran untuk berperan serta dalam memelihara, serta menjaga dan melestarikan lingkungan alam. (6) meningkatkan kesadaran untuk menghargai alam dan segala isinya sebagai ciptaan Tuhan. (7) memperoleh bekal pengetahuan, konsep dan ketrampilan IPA sebagai dasar untuk melanjutkan ke jenjang pendidikan selanjutnya, yaitu SMP/MTs.

Berdasarkan tujuan tersebut maka tugas seorang pendidik adalah bagaimana menerapkan beberapa ketrampilan mengajar agar seluruh tujuan pembelajaran dapat tercapai dalam mata pelajaran IPA. Selain itu pembelajaran IPA juga memberikan pengetahuan dasar tentang konsep yang bermanfaat dalam kehidupan sehari-hari.Kesulitan yang dialami guru pada saat mengajar materi IPA tema Pertanian adalah masih minimnya pengetahuan dan pemahaman peserta didik tentang Energi, serta kenampakan permukaan bumi sehingga peserta didik memiliki persepsi ganda dalam memahami materi tersebut. Berdasarkan masalah tersebut peneliti berkeinginan untuk melakukan perbaikan dalam pemberian pemahaman materi kepada peserta didik yaitu dengan cara kerjasama dengan orangtua peserta didik melalui penugasan, pendekatan pembelajaran, media yang digunakan dalam mengajar dan aktifitas peserta didik untuk menemukan pemahaman sendiri tentang materi pada saat pembelajaran juga lebih diutamakan.

Menurut Azizah (2013) guru harus mampu memberikan motivasi yang baik agar siswa menjadi lebih semangat untuk belajar dan lebih terangsang untuk menemukan hal-hal baru yang belum pernah mereka temui sebelumnya. Tujuan-tujuan pembelajaran juga harus jelas dan tepat agar pembelajaran dapat berhasil seperti yang diharapkan. Selain itu, kemampuan guru dalam mengarahkan perhatian, merangsang ingatan, menyediakan bimbingan, meningkatkan retensi, membantu transfer belajar dan memberikan umpan balik juga sangat mendukung keberhasilan pelaksanaan pembelajaran. Salah satu upaya untuk meningkatkan motivasi belajar peserta didik dalam mengajarkan materi pertanian yaitu menggunakan media pembelajaran yang menarik. Menurut Triastuti (2017) Kegiatan yang menyenangkan bagi siswa adalah bermain. Melihat kondisi yang ada di lapangan, maka guru perlu menghadirkan media yang dapat melibatkan siswa aktif dalam pembelajaran sehingga timbul motivasi belajar dalam diri siswa melalui kegiatan bermain atau permainan. Media tersebut dikemas semenarik mungkin dan disesuaikan dengan kebutuhan dan karakteristik siswa. Dengan demikian, diharapkan media pembelajaran tersebut dapat membantu siswa dalam mencapai tujuan pembelajaran yang lebih bermakna. Menurut Ribawati (2015) Penggunaan media yang selama ini dilakukan seperti bagan, peta konsep dan sejenisnya diduga membuat siswa bosan dan tidak menarik, di samping faktor-faktor lainnya. Hal ini dapat dimaklumi bahwa siswa tampak 
selalu menginginkan sesuatu yang baru dalam pembelajaran sepanjang pengetahuan peneliti yang telah bertugas selama ini. Menurut Febriani (2017) keberhasilan suatu proses pembelajaran tidak dapat terlepas dari media pembelajaran sebagai alat penunjang penyampaian informasi. Peserta didik yang masih dalam tahap operasional konkret memerlukan pembelajaran yang dapat membuat mereka mengingat dengan jelas pembelajaran yang sudah diajarkan, melalui media ini guru dapat memberikan sebuah inovasi baru dalam proses pembelajaran. Menurut Maisyarah (2019) Permainan sebagai suatu media pembelajaran memiliki beberapa kelebihan, diantaranya permainan adalah sesuatu yang untuk dilakukan, sesuatu yang menghibur. Permainan memungkinkan adanya partisipasi aktif dari peserta didik untuk belajar. Permainan memberikan pengalamanpengalaman nyata yang memancing peserta didik untuk lebih mampu aktif dan terampil dalam pembelajaran. Selain itu , dengan bermain peserta didik tidak akan merasa bosan dalam proses pembelajaran sehingga materi yang diajarkan oleh guru dalam proses pembelajaran mampu diterima dengan baik oleh peserta didik. Contohnya media visual sebagaimana dikatakan Yudhi (2013: 56) mengatakan bahwa media visual adalah media yang hanya melibatkan indera penglihatan. Termasuk dalam jenis media ini adalah media cetak-verbal, media cetak-grafis, dan media visual non-cetak. Sejalan dengan hal tersebut Levie dalam (Arsyad, 2013: 20) bahwa fungsi media visual adalah menarik dan mengarahkan perhatian peserta didik untuk berkonsentrasi kepada isi pelajaran yang berkaitan dengan makna visual yang ditampilkan atau menyertai teks materi pelajaran. Media disini dapat memperlancar pemahaman dan memperkuat ingatan sehingga peserta didik dapat lebih aktif dalam proses pembelajaran. Salah satu media visual yang dimaksud dalam penelitian ini adalah MEDOKA.

MEDOKA merupakan hasil karya mahasiswa UPGRIS angkatan tahun 2017 yang belum diuji cobakan untuk meningkatkan motivasi dan hasil belajar peserta didik. Pernah diujicobakan di SD N Ngablak 01 dan SD N Ngablak 02 dengan kelompok terbatas yaitu 30 dan 17 peserta didik. Media tersebut dikembangkan oleh Titik Murdhiyaningsih yang merupakan hasil penelitian dengan judul Pengembangan Media Otak Kata Tema Pertanian bagi Siswa Kelas IV Sekolah Dasar telah divalidasi oleh ahli baik dari aspek media maupun materi tema Pertanian. MEDOKA sendiri memiliki bentuk seperti buku yang terbuat dari bahan kertas multiplek yang tebal didalamnya terdapat puzzle yang memuat materi tentang IPA tema pertanian.

Berdasarkan pada pengembangan tersebut peneliti tertarik untuk mengetahui pengaruh MEDOKA terutama terhadap motivasi dan hasil belajar dengan melakukan penelitian dengan judul "Pengaruh MEDOKA Terhadap Motivasi Dan Hasil Belajar Tema Pertanian Pada Peserta didik Kelas IV SD Tambak 02 Karangdowo Klaten Tahun Pelajaran 2018/2019".

\section{Metode}

Pelaksanaan kegiatan penelitian pembelajaran dilaksanakan pada semester II di SDN Tambak 02 Karangdowo. Dalam hal ini penulis mengambil objek penelitiannya yaitu semua siswa kelas IV SDNTambak 02 Karangdowoyang terdiri dari 22 siswa. Penelitian ini adalah penelitian kuantitatif dengan desain Pre-Eksperimental Design dan jenis yang diambil adalah One-Group Pretest-Posttest Design. Pretest digunakan untuk mengetahui kondisi awal pada siswa sebelum diberi perlakuan dan setelah itu diberi perlakuan, setelah diberi perlakuan siswa diberi Posttest.

Tabel 1. Rancangan Desain One-Group Pretest-Posttest Design

\begin{tabular}{cccc}
\hline Kelompok & Tes & Perlakuan & Tes \\
\hline Siswa Kelas IV & Pretest & Pembelajaran menggunakan MEDOKA & Posttest \\
\hline
\end{tabular}

Teknik pengumpulan data yang digunakan dalam penelitian ini yaitu tes. Instrumen menggunakan tes (Pretest-Posttest) berupa tes pilihan ganda, kemudian obervasi dan dokumentasi yang dilakukan dalam kegiatan pembelajaran dikelas.

\section{Hasil dan Pembahasan}

Penelitian ini menggunakan desain Pre Experimental Design dengan bentuk One Group Pretest-Posttest. Kelas eksperimen diberikan perlakuan dengan menggunkan MEDOKA sedangkan kelas kontrol menggunakan model konvensional. Kelas eksperimen dan kelas kontrol diberikan soal pretest dan posttest. Soal yang diberikan untuk pretest dan posttest 
adalah soal pilihan ganda yang berjumlah 30 soal yang telah diuji validitas dan reliabilitas. Dalam penelitian ini, ada dua pertemuan untuk kelas eksperimen dan dua pertemuan dengan kelas kontrol dalam proses pembelajaran. Gagne dalam Suprijono (2014:2) mengemukakan "belajar adalah perubahan disposisi atau kemampuan yang dicapai seorang melalui aktivitas. Perubahan disposisi tersebut bukan diperoleh secara langsung oleh seseorang secara alami". Slameto (2010: 2) mengemukakan "belajar adalah suatu proses usaha yang dilakukan seseorang untuk memperoleh sesuatu perubahan tingkah laku yang baru secara keseluruhan, sebagai hasil pengalamannya sendiri dalam interaksi dengan lingkungannya". Sehingga dalam perlajaran kedua kelas tersebut mendapatkan perlakuan yang berbeda antara kelas control dan kelas eksperimen.

Sebelum pembelajaran menggunakan MEDOKA pada kelas eksperimen, peneliti terlebih dahulu membagikan soal pilihan ganda sejumlah 30 soal sebagai pretest dan angket motivasi belajar kepada siswa untuk dikerjakan. Penggunaan MEDOKA pada pembelajaran dilakukan peneliti dan diawali dengan kesiapan peserta didik dalam mengikuti pembelajaran dengan memperhatikan penjelasan dari guru dan siswa dibentuk menjadi 4 kelompok. Setelah dibentuk kelompok, peserta didik dalam kelompok di persilahkan untuk mencoba menggunakan MEDOKA agar lebih memahami pembelajarn yang telah diberikan. Karena keterbatasan media, maka MEDOKA digunakan secara bergantian dan semua bisa mencoba menggunakannya. Kemudian setelah semua siswa dalam kelompok mencoba menggunakan MEDOKA, pada saat mencoba menggunakan MEDOKA peserta didik terlihat sangat antusias. Seteah semua mencoba guru memberikan soal yang dikerjakan secara berkelompok, dan setelah selesai mengerjakan setiap kelompok mempresentasikan di depan kelas. Pada akhir pertemuan peserta didik diberikan soal posttest untuk mengetahui apakah penerapan penggunaan MEDOKA dapat meningkatkan motivasi dan hasil belajar siswa kelas IV SDN 2 Tambak.

Perhitungan yang digunakan untuk mengetahui normalitas sempel adalah populasi dilakukan dengan uji lelifors, pada tarif signifikan 5\%. Data hasil pretest kemudian diujikan dengan uji normalitas data awal untuk mengetahui apakah sampel berasal dari populasi berdistribusi normal atau tidak. Berdasarkan uji normalitas awal kelas eksperimen diperoleh $L_{0}=0,106$ dengan $n=22$ dan tarif nyata $\alpha=0,05$, dari daftar nilai kritis $L$ di dapat $L_{\text {tabel }}=$ 0,190 . Karena $L_{0}<L_{\text {tabel }}$ yaitu $0,106<0,190$, maka $H_{0}$ diterima sehingga dapat disimpulkan bahwa sempel berasal dari populasi berdistribusi normal. Kemudian pada tahap akhir kelas eksperimen dilakukan kembali uji normalitas dengan menggunakan posttest. Berdasarkan perhitungan diperoleh $L_{0}<L_{\text {tabelyaitu }} 0,102<0,190$, maka $H_{0}$ diterima sehingga dapat disimpulkakn bahwa sampel berasal dari populasi berdistribusi normal.

Pada kelas kontrol juga dilakukan uji normalitas awal. Berdasarkan uji normalitas awal kelas kontrol diperoleh $L_{0}=0,149$ dengan $n=22$ dan taraf nyata $\alpha=0,05$, dari daftar kritis $L$ didapat $L_{\text {tabel }}=0,190$. Karena $L_{0}<L_{\text {tabel }}$ yaitu $0,149<0,190$, maka $H_{0}$ diterima sehingga dapat disimpulkan bahwa sempel berasal dari populasi berdistribusi normal. Kemudian pada uji normalitas tahap akhir kelas kontrol perhitungan diperoleh $\mathrm{L}_{0}<\mathrm{L}_{\text {tabel }}$ yaitu $0,140<0,190$, maka $\mathrm{H}_{0}$ diterima sehingga dapat disimpulkakn bahwa sampel berasal dari populasi berdistribusi normal. Nilai rata-rata pretest hasil belajar kelas eksprimen memperoleh 73,863 sedangkan nilai rata-rata pretest kelas kontrol diperoleh 60,454.

Perhitungan uji regresi linear sederhana diperoleh nilai $F_{\text {hitung }}$ sebesar 887,5745 dan nilai $F_{\text {tabel }}$ sebesar 4,35, karena $F_{\text {hitung }}>F_{\text {tabel }}$ yaitu 887,5745 $>4,35$ maka $\mathrm{H}_{0}$ ditolak dan $\mathrm{H}_{\mathrm{a}}$ diterima. Sehingga hipotesisnya ada pengaruh positif antara MEDOKA terhadap hasil belajar tema selalu berhemat energi peserta didik kelas IV SDN 2 Tambak Karangdowo. Penelitian ini didasarkan pada teori Gagne (Dalam Dahar Wilis, 2011:31) sehingga dapat disimpulkan bahwa siswa dikatakan berhasil belajar karena siswa dapat memahani materi yang disampaikan oleh guru melalui pengalaman mengingat dan menempel serta dibuktikan dengan meningkatkan motivasi dan hasil belajar peserta didik tema Selalu Berhemat Energi kelas IV SDN Tambak 02 Karangdowo Klaten sehingga telah mencapai KKM yang ditentukan.

\section{Kesimpulan}

Berdasarkan hasil penelitian dan pembahasan yang telah dikemukakan dengan analisis data uji prasyarat regresi linier sederhana dapat disimpulkan bahwa terdapat pengaruh yang signifikan antara penggunaan MEDOKA terhadap hasil belajar yaitu sebesar $30 \%$. Pencapaian penelitian ini dapat tercapai terlihat pada rata-rata posttest hasil belajar pada mata 
pelajaran IPA tema Selalu Berhemat Energi siswa kelas eksperimen lebih baik dari kelas kontrol yaitu dapat dilihat bahwa rata-rata nilai posttest kelas eksperimen sebesar 82,045 sedangkan rata-rata nilai posttestkelas kontrol sebesar 79,091.

\section{Daftar Pustaka}

Arikunto, Suharsimi. 2013.Prosedur Penelitian Suatu Pendekatan Praktik. Jakarta: Rineka Cipta.

2009. Evaluasi Program Pendidikan.Jakarta: PT Bumi Aksara.

Arsyad, Azhar. 2013. Media Pembelajaran. Jakarta: PT Raja Grafindo Persada.

Azizah, Nur, Julianto. 2013. Penerapan Media Monopoli untuk Meningkatkan Hasil Belajar Siswa pada Mata Pelajaran IPA di Sekolah Dasar. JPGSD Vol. 01 No. 02 Hal. 1-12. https://jurnalmahasiswa.unesa.ac.id/index.php/. Diakses 20 Mei 2019.

BSNP.2006. Standar Isi Sekolah Dasar/Madrasah Ibtidaiyah.Jakarta: Balitbang.

Dahar, Ratna Willis. 2011. Teori-Teori Belajar \& Pembelajaran. Jakarta: Erlangga. Djamarah, Syaiful Bahri. 2011. Psikologi Belajar. Jakarta: PT Rineka Cipta.

Djamarah, Syaiful Bahri. 2011. Psikologi Belajar. Jakarta: PT Rineka Cipta.

Fatthurrohman, Muhammad dan Sulistyorini. 2012. Belajar dan Pembelajaran. Yogyakarta: Teras.

Febriani, Corry. 2017. Pengaruh Media Video terhadap Motivasi Belajar dan Hasil Belajar Kognitif Pembelajaran IPA Kelas V Sekolah Dasar. Jurnal Prima Edukasia, 5 (1), 2017, 11-21. http://journal.uny.ac.id/index.php/ipe. Diakses 20 Mei 2019.

Hamdu, Ghulam, Lisa Agustina. 2011. Pengaruh Motivasi Belajar Peserta didik Terhadap Prestasi Belajar IPA Di Sekolah Dasar. Jurnal Penelitian Pendidikan

Hamalik, Oemar. 2013. Kurikulum dan Pembelajaran. Jakarta: Bumi aksara.

Hamzah. B. Uno. (2013). Teori Motivasi dan Pengukurannya. Jakarta. Bumi Aksara

Komsatun, Ani. 2014. Pengaruh penggunaan teknik Mind Map terhadap motivasi belajar IPS peserta didik kelas IV SD N I Srandakan Bantul tahun ajaran 2014/2015. Jurnal Pedagogik Vol I, No 1. https://ejournal.uny.net/.Diakses 07 Desember 2018 Pukul 20.00 WIB.

Maisyarah, Elke, Firman Firman. 2019. Media Permainan Ular Tangga, Motivasi Dan Hasil Belajar Peserta Didik Di Sekolah Dasar. https://www.researchgate.net/publication/. Diakses 20 Mei 2019.

Mudali Marga, Kristina, dkk. 2018. Pengaruh Media Kokami (Kotak Dan Kartu Misterius) terhadap Keterampilan Berpikir Kritis dan Motivasi Belajar Siswa Kelas VIII SMP Negeri 19 Mataram Tahun Pelajaran 2017/2018. Jurnal Hasil Kajian, Inovasi, dan Aplikasi Pendidikan Fisika Vol. 4, No. 2 Hal. 18-25. https://media.neliti.com/media/publications/. Diakses 20 Mei 2019.

Murdhiyaningsih, Titik.2017.Penerapan MEDOKA Pada Tema Pertanian Peserta didik Kelas IV SD N 01 Kayen Pati". Skripsi.Semarang:UPGRIS.

Ratnawulan, Elis dan Rusdiana. 2014. Evaluasi Pembelajaran. Bandung: Pustaka Setia. https://PDFdigilid.uinsgd.ac.id.Diakses 25 September 2018 Pukul 12.30 WIB. 
Ribawati, Eko. 2015. Pengaruh Penggunaan Media Video terhadap Motivasi dan Hasil Belajar Siswa. Jurnal "Candrasangkala", Vol. 1 No. 1 Hal. 1-12. http://jurnal.untirta.ac.id/index.php/. Diakses 20 Mei 2019.

Rikmasari, Rima. 2014. "Pengaruh Penggunaan Media Kartun Terhadap Motivasi Belajar Peserta didik pada Mata Pelajaran Bahasa Indonesia Kelas IV SDN.

Rosita Wati, S. 2008. Senang Belajar Ilmu Pengetahun Alam untuk kelas IV Sekolah Dasar/Madrasah Ibtidaiyah. Jakarta: Pusat Pembukuan, Departemen Pendidikan Nasional

Jayasakti 06 Kecamatan Muaragembong Kabupaten Bekasi”. Jurnal Pedagogik Vol II, No 1. https://ejournal.unisma.net/.Diakses 07 September 2018 Pukul 08.12 WIB.

Trianto, (2007). Model-model Pembelajaran Inovatif berorientasi konstuktivistik. Prestasi Pustaka.Jakarta

Triastuti, Desty, dkk. 2017. Penggunaan Media Papan Permainan untuk Meningkatkan Motivasi Belajar Siswa di Sekolah Dasar. http://pasca.um.ac.id/conferences/index.php/. Diakses 20 Mei 2019.

Sadiman, Arief S dkk. 2011. Media Pendidikan: Pengertian, Pengembangan dan Pemanfaatannya. Jakarta: Rajawali Pers.

Sadiman, Arief S dkk. 2011. Media Pendidikan: Pengertian, Pengembangan dan Pemanfaatannya. Jakarta: Rajawali Pers.

Sardiman, A.M. 2014. Interaksi dan motivasi belajar mengajar. Jakarta: Rajawali.

Siregar, Eveline dan Hartini Nara.2014. Teori Belajar dan Pembelajaran. Bogor: Ghalia Indonesia.

Slameto. 2010. Belajar \& Faktor-Faktor yang Mempengaruhi. Jakarta: Rineka Cipta.

Sudjana. 2005. Metode Statistika. Bandung: PT Tarsito.

Sugiyono. 2016. Metode Penelitian Kuantitatif, Kualitatif, dan R\&D. Bandung: Alfabeta.

Sukmadinata, Nana Syaodih. 2016. Metode Penelitian Pendidikan. Bandung: PT Remaja Rosdakarya.

Suprijono, Agus. 2012. Cooperative Learning Teori \& Aplikasi Paikem. Yogyakarta: Pustaka Belajar. 